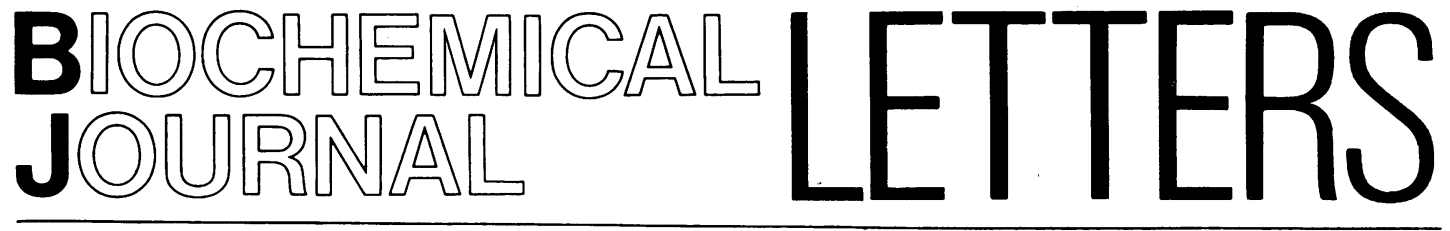

\section{Problems associated with}

assessment of the effect of GDP
upon hormone stimulation of
adenylate cyclase

It is known that in mammalian adenylate cyclase systems the physiological potentiator of hormonal stimulation of this transmembrane complex is GTP. Cassel \& Selinger (1976) suggested that a feature of such systems would be the presence of hormonestimulated GTPase activity and postulated that GDP would be inhibitory to hormonal stimulation. Subsequent reports have indicated that GDP may be able to exert a limited coupling of the hormonal signal to the catalytic subunit.

The problems associated with the ability of ATP, the substrate of adenylate cyclase, to allow GDP to be converted to GTP either by endogenous phosphorylating systems or by the nucleoside triphosphate regenerating system used to preserve ATP levels have been correctly pointed out (e.g. Iyengar \& Birnbaumer, 1979). Previous workers have sought to overcome such problems by trying to eliminate the conversion of GDP to GTP during the assay by using $\mathrm{p}[\mathrm{NH}] \mathrm{ppA}$, a non-phosphorylating analogue of ATP, as substrate and by omitting the ATPregenerating system from the assay.

The gonadotropin-sensitive adenylate cyclase of bovine corpus luteum has been studied in this laboratory. (Lydon et al., 1981a, b; Murphy \& Stansfield, 1984). The inclusion of $\mathrm{p}[\mathrm{NH}] \mathrm{ppA}$ as substrate in such assays yielded no detectable basal cyclic AMP production and extremely low level production even in the presence of human choriogonadotropin and GTP (G. J. Murphy \& D. A. Stansfield, unpublished work.) Upon checking the literature it became apparent that many groups had reported deficiencies in the substrate potential of $\mathrm{p}[\mathrm{NH}] \mathrm{ppA}$ [renal medulla, Birnbaumer \& Yang (1974); adrenal cortex, Londos \& Rodbell (1975); neuroblastoma, Blume \& Foster (1976); liver, Kimura \& Nagata (1979); thyroid, Totsuka et al. (1983)]. The adenylate cyclase activity in the presence of $\mathrm{p}[\mathrm{NH}] \mathrm{ppA}$ ranged from 5 to $50 \%$ of that observed in the presence of ATP in these experiments, and basal activity was frequently undetectable. Only Rodbell et al. (1971) appear to have

Abbreviation used: $\mathrm{p}[\mathrm{NH}] \mathrm{ppA}$, adenosine $5^{\prime}-[\beta, \gamma-$ imido]triphosphate. observed parity of substrate potential between $\mathrm{p}[\mathrm{NH}] \mathrm{ppA}$ and ATP; this could have been caused by the presence of $\mathrm{p}[\mathrm{NH}] \mathrm{ppG}$-like stimulatory contaminants in impure p[NH]ppA (Clark, 1978; Baker \& Potter, 1981). Birnbaumer \& Yang (1974) have suggested reasons for the poor performance of $\mathrm{p}[\mathrm{NH}] \mathrm{ppA}$ as a substrate for adenylate cyclase.

The inefficiency of $\mathrm{p}[\mathrm{NH}] \mathrm{ppA}$ as a substrate for adenylate cyclase might have been of little moment had workers used it as substrate for adenylate cyclase with subsequent measurement of cyclic AMP formation by competitive protein binding las did Kimura \& Nagata (1979) and ourselvesl or radioimmunoassay, or had they continued to use $\left[\alpha-{ }^{32} \mathrm{P}\right] \mathrm{p}[\mathrm{NH}] \mathrm{ppA}$ with subsequent measurement of cyclic [ ${ }^{32}$ P]AMP formation [as did Birnbaumer \& Yang (1974) and Totsuka et al. (1983)].

However, we are disturbed by what has actually happened. Iyengar \& Birnbaumer (1979), Iyengar et al. $(1980 a, b)$, Birnbaumer et al. (1980) and Goldhammer \& Wolff (1982) have used p[NH]ppA as the bulk substrate with $\left[\alpha^{-32} \mathrm{P}\right] \mathrm{ATP}$ as radiotracer. Because of the inefficiency of $\mathrm{p}[\mathrm{NH}] \mathrm{ppA}$ relative to ATP as substrate for adenylate cyclase, and because of the phosphorylation potential of ATP in transphosphorylation reactions with GDP, at least two serious consequences may have arisen.

(a) $\left[\alpha-{ }^{32} \mathrm{P}\right] \mathrm{ATP}$ may have been utilized as substrate in preference to $\mathrm{p}[\mathrm{NH}] \mathrm{ppA}$, and the radioactivity of cyclic $\left.{ }^{32} \mathrm{P}\right] \mathrm{AMP}$ formed may bear no relationship to the actual cyclic AMP formation in molar terms.

(b) The presence of up to $10 \mu \mathrm{M}$-ATP as tracer could cause the formation of up to $10 \mu \mathrm{M}-\mathrm{GTP}$ from the GDP whose effect is being studied if phosphotransferase activities exist in the plasma membrane preparation. Not only would the amount of the radio-tracer diminish, causing the actual 'specific radioactivity' of the heterogeneous substrate mixture to fall to an unknown value, but up to $10 \mu \mathrm{M}$-GTP would also appear in the assay as a potential stimulator of adenylate cyclase activity. Transphosphorylation from tracer ATP to GTP has been shown by Totsuka et al. (1983).

Iyengar et al. (1980b) admit that the heterogeneous substrate mixture makes it impossible to carry out GDP concentration-effect studies; at low GDP concentrations the effects observed would be mainly due to GTP formed by transphosphorylation activities. In fact, even if only $5 \%$ conversion of $100 \mu \mathrm{M}$-GDP to GTP occurred the 
adenylate cyclase would have been assayed in the presence of $5 \mu \mathrm{M}$-GTP and the tracer level would have been decreased by $5 \mu \mathrm{M}$. In this paper the authors state that they express their results as c.p.m. of cyclic [ $\left.{ }^{32} \mathrm{P}\right] \mathrm{AMP}$ formed rather than as pmol of cyclic $\left.{ }^{32} \mathrm{P}\right] \mathrm{AMP}$ formed, implicitly admitting that conversion of $\mathrm{p}[\mathrm{NH}] \mathrm{ppA}$ to cyclic AMP was not assessable in their system, but they go on to say: 'Since, unless otherwise stated, the assays were carried out at a specific radioactivity of total adenine nucleotide (AMP-P(NH)-P plus ATP) of $10^{4}$ counts $/ 5 \mathrm{~min} / \mathrm{pmol}$, the numerical values reported are also equivalent to the picomoles of cyclic AMP formed $/ \mathrm{min} / \mathrm{mg}$ of protein if it is assumed that the accumulation rates were constant with time and both $A T P$ and AMP-P $(N H)-P$ serve as substrate with equal efficiency' [our italics].

Birnbaumer et al. (1980) used the heterogeneous substrate mixture to show that GDP reduced the activation caused by GTP in cholera toxin/NAD ${ }^{+}$ treated membranes. Depletion of the preferred substrate, $\left[\gamma^{32} \mathrm{P}\right]$ ATP, is as likely to have caused the reduction of activity as a direct effect of GDP at the regulatory site. Iyengar et al. (1980a) used the heterogeneous substrate mixture to show that GDP supported hormonal stimulation of liver and S49 cell adenylate cyclase. Conversion of GDP to GTP was said not to have occurred because Iyengar \& Birnbaumer (1979) had shown retention of $[\alpha-$ $\left.{ }^{32} \mathrm{P}\right] \mathrm{GDP}$ and $\left[\alpha^{32} \mathrm{P}\right] \mathrm{GTP}$ in parallel experiments from which $\left[\alpha^{-32} \mathrm{P}\right]$ ATP had been omitted. Thus the conversion of GDP to GTP at the expense of tracer ATP was not excluded as they appear to have believed, and hormonal stimulation could have been influenced by such GTP. Goldhammer \& Wolff (1982) make no comments to alert their readers to the dangers of the heterogeneous substrate mixture.

Overall, experiments using the heterogeneous substrate mixture have indicated partial promotion of hormonal stimulation by GDP in liver, S49 cells and corpus luteum, failure to couple in turkey erythrocytes; and inhibition of adenylate cyclase stimulation in neuroblastoma cells (Iyengar et al., $1980 a, b$; Iyengar \& Birnbaumer, 1979).

Rodbell et al: (1971) using p[NH]ppA alone as substrate reported that GDP was as effective as GTP in promoting hormonal coupling of liver adenylate cyclase, whereas Kimura \& Nagata (1979), also using $\mathrm{p}[\mathrm{NH}] \mathrm{ppA}$ as sole substrate, observed only partial coupling by GDP in the same tissue. Kimura \& Shimada (1980) say that this latter report of partial coupling by GDP: ‘... was absolutely dependent on the formation of GTP from GDP by transphosphorylation ...', which appears to be a considerable hardening of their original contention that the GDP effects could have been due to GTP derived from GDP and a phosphatedonating contaminant of $\mathrm{p}[\mathrm{NH}] \mathrm{ppA}$. However, Totsuka et al. (1983) claim that there is no conversion of GDP to GTP by thyroid membranes in the presence of $\mathrm{p}[\mathrm{NH}] \mathrm{ppA}$ alone; not only was GDP incapable of supporting stimulation of thyroid adenylate cyclase by TSH (thyrotropin), it actually inhibited both basal- and TSH-stimulated activities. Kimura \& Shimada (1983) point out the perils of the heterogeneous substrate mixture and the problems of using $\mathrm{p}[\mathrm{NH} \mid \mathrm{ppA}$, even on its own, as substrate.

It would appear that much of the work performed with the heterogeneous $\mathrm{p}[\mathrm{NH}] \mathrm{ppA} /\left[\alpha^{-32} \mathrm{P}\right] \mathrm{ATP}$ system must now be viewed with caution and should be re-investigated using the methodology of Kimura \& Shimada (1983). Adenosine $5^{\prime}$-[ $\gamma$-thio $]$-triphosphate (ATS[S]) is utilized in phosphotransferase reactions and cannot be used in studies of GDP effects (G. J. Murphy \& D. A. Stansfield, unpublished work).

Gregory J. MURPHY and David A. STANSFIELD Department of Biochemistry, Medical Sciences Institute, University of Dundee, Dundee DD1 4HN, Scotland, U.K.

\section{(Received 13 June 1983)}

Baker, S. P. \& Potter, L. T. (1981) J. Biol. Chem. 256, 7925-7931

Birnbaumer, L. \& Yang, P.-C. (1974) J. Biol. Chem. 249, 7848-7856

Birnbaumer, L, Swartz, T. L., Abramowitz, J., Mintz, P. W. \& Iyengar, R. (1980) J. Biol. Chem. 255, 35423551

Blume, A. J. \& Foster, C. J. (1976) J. Biol. Chem. 251, 3399-3404

Cassel, D. \& Selinger, Z. (1976) Biochim. Biophys. Acta 452, 538-551

Clark, R. B. (1978) J. Cyclic Nucleotide Res. 4, 259-270

Goldhammer, A. \& Wolff, J. (1982) Biochim. Biophys. Acta 701, 192-199

Iyengar, R. \& Birnbaumer, L. (1979) Proc. Natl. Acad. Sci. U.S.A. 76, 3189-3193

Iyengar, R, Abramowitz, J., Bordelon-Riser, M. \& Birnbaumer, L. (1980a) J. Biol. Chem. 255, 35583564

Iyengar, R., Abramowitz, J., Bordelon-Riser, M., Blume, A. J. \& Birnbaumer, L. (1980b) J. Biol. Chem. 255, 10312-10321

Kimura, N. \& Nagata, N. (1979) J. Biol. Chem. 254, $3451-3457$

Kimura, N. \& Shimada, N. (1980) FEBS Lett. 117, $172-174$

Kimura, N. \& Shimada, N. (1983) J. Biol. Chem. 258, 2278-2283

Londos, C. \& Rodbell, M. (1975) J. Biol. Chem. 250, 3459-3465

Lydon, N. B., Young, J. L. \& Stansfield, D. A. (1981a) Biochem. J. 198, 631-638

Lydon, N. B., Young, J. L. \& Stansfield, D. A. (1981b) Adv. Cyclic Nucleotide Res. 14, 658

Murphy, G. J. \& Stansfield, D. A. (1984) Biochem. Soc. Trans. 12, in the press

Rodbell, M., Birnbaumer, L., Pohl, S. L. \& Krans, H. M. J. (1971) J. Biol. Chem. 246, 1877-1882

Totsuka, Y., Nielsen, T. B. \& Field, J. B. (1983) Biochim. Biophys. Acta 718, 135-143 